\title{
Visceral Medicine
}

Founded in 1984 as "Chirurgische Gastroenterologie mit interdisziplinären Gesprächen" by

A. Akovbiantz, H. Denk, K.-J. Paquet and C.E. Zöckler

\section{Editors-in-Chief}

Ernst Klar, MD, FACS - Department of General, Thoracic, Vascular and Transplantation Surgery, Rostock University Medical Center, Rostock, Germany

Georg Kähler, MD - Central Interdisciplinary Endoscopy, University Medical Center Mannheim, Medical Faculty Mannheim, Heidelberg University, Mannheim, Germany

Markus F. Neurath, MD - Department of Internal Medicine, Friedrich-Alexander University Erlangen-Nürnberg, University Medical Center Erlangen, Erlangen, Germany

\section{Honorary Editors}

Reinhard Bittner, MD, FRCS - Hernia Center, Winghofer Medicum, Rottenburg am Neckar, Germany Karl-Joseph Paquet, MD, FACS - Bad Kissingen, Germany

Jürgen F. Riemann, MD, FACP - Department of Medicine C, Hospital of the City Ludwigshafen/ Rhine, Ludwigshafen, \& Stiftung Lebensblicke, Ludwigshafen, Germany

\section{Editorial Advisory Board Members}

Michael Betzler, MD, PhD, FACS - Essen, Germany

Jacob R. Izbicki, MD, FACS, FRCSEd (Hon) - Department of General, Visceral and Thoracic Surgery, University Medical Center Hamburg-Eppendorf, University of Hamburg, Hamburg, Germany Peter Malfertheiner, MD - Department of Gastroenterology, Hepatology and Infectious Diseases, Otto von Guericke University, Magdeburg, Germany

Hans-Joachim Meyer, MD, MD h.c., FACS - German Society of Surgery, Berlin, Germany Joachim Mössner, MD - Division of Gastroenterology and Rheumatology, Department of Medicine, Neurology and Dermatology, University Hospitals of Leipzig AöR, Leipzig, Germany Michael H. Schoenberg, MD - Medical Center for Optimized Cancer Therapy, Munich, Germany Albert Tuchmann, MD, FACS - Secretary General, Austrian Society of Surgery, \& Consultant Surgeon, Vienna, Austria

\section{Editorial Board}

Hans-Dieter Allescher, MD - Center for Internal Medicine, Clinic Garmisch-Partenkirchen, Academic Teaching Hospital of Ludwig Maximilians University Munich, Garmisch-Partenkirchen, Germany Tilo Andus, MD - Department of Internal Medicine, Gastroenterology, Hepatology and Oncology, Klinikum Stuttgart - Krankenhaus Bad Cannstatt, Stuttgart, Germany

Official Organ of

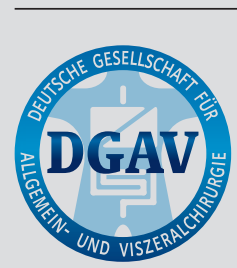

Associated Organ for Continuing Education
Maximilian Bockhorn, MD - Department of General and Visceral Surgery, University Medical Center Oldenburg, University of Oldenburg, Oldenburg, Germany

Markus W. Büchler, MD, FACS (Hon) - Department of General, Visceral and Transplantation Surgery, University of Heidelberg, Heidelberg, Germany

Seung-Hun Chon, MD - Department of General, Visceral, Tumor and Transplantation Surgery, University Hospital Cologne, Cologne, Germany

Pierre-Alain Clavien, MD, FACS (Hon) - Department of Visceral and Transplantation Surgery, University Hospital Zurich, Zurich, Switzerland

\section{Karger"}


Silvio Danese, MD PhD - Inflammatory Bowel Disease Clinical and Research Unit, Humanitas Research Hospital, Rozzano, Milan, Italy

Ulrike W. Denzer, MD - Department of Internal Medicine, University Hospital Gießen-Marburg, Marburg, Germany

Wolfgang Fischbach, MD, PhD - Department of Internal Medicine and Palliative Care Unit, Clinic Aschaffenburg, Academic Teaching Hospital of the University of Würzburg, Aschaffenburg, Germany

Helmut Friess, MD - Department of Surgery, Technical University of Munich, Munich, Germany

Andrea Frilling, MD, PhD, FACS, FRCS, FEBS - Department of Surgery and Cancer, Imperial College London, London, UK

Guido Gerken, MD - Department of Gastroenterology and Hepatology, University Hospital Essen, University Duisburg-Essen, Essen, Germany

Ines Gockel, MD - Department of Visceral, Transplantation, Thorax and Vascular Surgery, University Hospitals of Leipzig AöR, Leipzig, Germany

Thomas Matthias Gress, MD - Department of Gastroenterology and Endocrinology, Philipps University Marburg, Marburg, Germany

Felix Gundling, MD - Department of Internal Medicine - Gastroenterology, Diabetology and Endocrinology, Kemperhof, Gemeinschaftsklinkum Mittelrhein gGmbH, Koblenz, Germany

Thilo Hackert, MD - Department of Surgery, University Hospital Heidelberg, Heidelberg, Germany

Samuel Huber, MD - I. Department of Medicine, University Medical Center Hamburg-Eppendorf, Hamburg, Germany

Joachim Jähne, MD, FACS, MBA - Clinic for General and Visceral Surgery, Center for Endocrine and Oncological Surgery, Diakovere Henriettenstift Hannover, Hanover, Germany

Sergey Kashin, MD - Endoscopy Department, Yaroslavl Regional Cancer Hospital, Yaroslavl, Russian Federation

Tobias Keck, MD, MBA, FACS - Department of Surgery, University Medical Center Schleswig-Holstein, Campus Lübeck, Lübeck, Germany

Wolfram T. Knoefel, MD - Department of General, Visceral and Pediatric Surgery, University Hospital Düsseldorf, Düsseldorf, Germany

Ferdinand Köckerling, MD - Department of General, Visceral and Vascular Surgery, Vivantes Klinikum Spandau, Berlin, Germany

Marko Kornmann, MD - Department of General and Visceral Surgery, University Hospital UIm, UIm Germany

Roland S. Kroner, MD - Department of General, Visceral and Vascular Surgery, University Hospital, Otto von Guericke University Magdeburg, Magdeburg, Germany

Florian Kühn, MD - Department of General, Visceral, Transplantation, Vascular and Thoracic Surgery, Clinic Grosshadern, Ludwig Maximilians University of Munich, Munich, Germany

Frank Lammert, MD, FEBG - Vorstand für Krankenversorgung, Medizinische Hochschule Hannover, Hannover, Germany

Jessica Leers, MD - Department of General, Visceral, Tumor and Transplantation Surgery, University Hospital Cologne, Cologne, Germany

Markus M. Lerch, MD, FRCP, FACG - Department of Medicine A, University Medicine, Ernst Moritz Arndt University, Greifswald, Germany

Karl-Heinrich Link, MD, PhD - Surgical Center, Department of General and Visceral Surgery, Asklepios Tumor Center, Asklepios Paulinen Clinic, Wiesbaden, Germany

Ansgar W. Lohse, MD - I. Department of Medicine, University Medical Center Hamburg-Eppendorf, Hamburg, Germany

Nisar Peter Malek, MD - Department of Internal Medicine I, Medical University Hospital, Tübingen, Germany

Andrea May, MD, PhD - Department for Gastroenterology, Hematology/Oncology and Pneumology, Asklepios Paulinen Klinik Wiesbaden, Wiesbaden, Germany

Martina Müller-Schilling, MD - Department of Internal Medicine I, University Medical Center, Regensburg, Germany 
Karl J. Oldhafer, MD - Department of General and Visceral Surgery, Aklepios Hospital Barmbek, Hamburg, Germany

Hans-Rudolf Raab, MD - Oldenburg, Germany

Beate Rau, MD, PhD, MBA - Department of Surgery, Campus Mitte, Charité - University of Berlin, Berlin, Germany

Jens Ricke, MD - Department of Clinical Radiology, Medical Center of the Ludwig-Maximilian University, Munich, Germany

Anjali A. Röth, MD, MSc - Department of General, Visceral and Transplantation Surgery, University Hospital Aachen, Aachen, Germany

Gerhard Rogler, MD, PhD - Division of Gastroenterology and Hepatology, Zurich University Hospital, Zurich, Switzerland

Peush Sahni, MBBS, PhD - Department of Gastrointestinal Surgery, All India Institute of Medical Sciences, New Delhi, India

Hans-Konrad Schackert, MD - Department of Surgical Research, University Hospital Carl Gustav Carus, Technical University Dresden, Dresden, Germany

Peter Schemmer, MD - Department of Transplantation Surgery, University Hospital for Surgery, Graz, Austria

Hans Scherübl, MD - Department of Gastroenterology, Gastrointestinal Oncology and Infectious Diseases, Vivantes Clinic Am Urban, Berlin, Germany

Hans J. Schlitt, MD, ML, FACS, FRCS (Eng), FICS, FEBS, MHM - Department of Surgery, University Hospital Regensburg, Regensburg, Germany

Beate K. Straub, MD - Institute of Pathology, Johannes Gutenberg University Mainz, Mainz, Germany Kęstutis Strupas, MD, PhD - Clinic of Gastroenterology, Nephrourology and Surgery, Center of Abdominal Surgery, Faculty of Medicine, Vilnius University, Santariskiu Clinics, Vilnius, Lithuania

Andrea Tannapfel, MD - Institute of Pathology, Ruhr-University Bochum, Bochum, Germany

Herbert Tilg, MD - Department of Internal Medicine, University Hospital for Internal Medicine I, Innsbruck Medical University, Innsbruck, Austria

Michael Trauner, MD, FAASLD, AGAF - Division of Gastroenterology and Hepatology, Department of Internal Medicine III, Medical University of Vienna, Vienna, Austria

Andrew L. Warshaw, MD, FACS, FRCSEd (Hon) - Department of Surgery, Massachusetts General Hospital, Harvard Medical School, Boston, MA, USA

Edris Wedi, MD - Sana Klinik Offenbach, Offenbach, Germany

Benjamin Weixler, MD - Department of General, Visceral and Vascular Surgery, Campus Benjamin Franklin, Charité - University of Berlin, Berlin, Germany

Jens Werner, MD - Department of General, Visceral, Transplantation, Vascular and Thoracic Surgery, Clinic Grosshadern, Ludwig Maximilians University of Munich, Munich, Germany

Yuzo Yamamoto, MD, PhD - Department of Gastroenterological Surgery, Akita University Graduate School of Medicine, Akita, Japan

Stefan Zeuzem, MD - Department of Medicine, Goethe University Hospital, Frankfurt/M., Germany

\section{Editorial Office}

Yvonne Rebmann

S. Karger AG

P.O. Box

CH-4009 Basel (Switzerland)

vis@karger.com 
Review Article

63 SARS-CoV-2 Virus Manifestations in the Gastrointestinal Tract: Therapeutic Implications Jefremow, A.; Neurath, M.F. (Erlangen)

Research Articles

70 Evaluating a Clinical Pathway in Laparoscopic Cholecystectomy: Effective in Reducing Complications? A Propensity Score Matching Analysis Arabacioglu, D. (Langen); Lehn, A.; Herrmann, E. (Frankfurt); Albers, B.; Hanisch, E.; Buia, A. (Langen)

77 Computed Tomography-Based Tumor Heterogeneity Analysis Reveals Differences in a Cohort with Advanced Pancreatic Carcinoma under Palliative Chemotherapy

Steinacker, J.P.; Steinacker-Stanescu, N.; Ettrich, T.; Kornmann, M.; Kneer, K.; Beer, A.; Beer, M.; Schmidt, S.A. (Ulm)

84 PharmaNews

No. 2

Research Articles

87 Sequential Systemic Treatment in Advanced Hepatocellular Carcinoma Is Able to Prolong Median Survival to More than 3 Years in a Selected Real-World Cohort

von Felden, J.; Karkmann, K.; Ittrich, H.; Gil-Ibanez, I.;

Fründt, T.; Krause, J.; Lohse, A. W.; Wege, H.; Schulze, K.

(Hamburg)

Focus Article

94 Preoperative Liver Function Guiding HCC Resection in Normal and Cirrhotic Liver

Anger, F.; Klein, I.; Löb, S.; Wiegering, A.; Singh, G.; Sperl, D.; Götze, O.; Geier, A.; Lock, J.F. (Würzburg)

Focus Article

48 Improving Outcomes in Perihilar Cholangiocarcinoma Oldhafer, K.J.; von Hahn, T. (Hamburg); Arvanitakis, M. (Brussels); Nagino, M. (Nagoya); Torres, O.J.M. (Maranhão) Focus Article

Clinical Therapeutic Review

52 Bleeding Duodenal Ulcer: Strategies in High-Risk Ulcers

Mille, M.; Engelhardt, T.; Stier, A. (Erfurt)
102 Predictors of 90-Day Mortality following Hepatic Resection for Hepatocellular Carcinoma Lei, G.Y.; Shen, L.; Junnarkar, S.P.; Huey, C.T.; Low, J.; Shelat, V.G. (Singapore) Focus Article

110 SEC62 and SEC63 Expression in Hepatocellular Carcinoma and Tumor-Surrounding Liver Tissue Casper, M.; Linxweiler, M.; Linxweiler, J.; Zimmermann, R.; Glanemann, M.; Lammert, F.; Weber, S.N. (Homburg) Focus Article 
Case Report

116 A Hepatocellular Carcinoma Patient with TSC1 Mutations Benefits from Treatment with Everolimus: A Case Report

Shi, H.-S.; Wang, S.; Li, M.-J.; Wu, L.-Q. (Qingdao)

Focus Article

Research Articles

120 Adult Intussusception: An Uncommon Condition and Challenging Management

Tarchouli, M. (Agadir/Fez); Ait Ali, A. (Rabat)

128 Impact of Anal Fissure on Neuroticism, Extraversion, Openness to Experience, Agreeableness, and Conscientiousness: A Case-Control Study

Luri-Prieto, P.; Candela-Gomis, A.; Palazón-Bru, A.; Navarro-Cremades, F.; Gil-Guillén, V.F.; Compañ-Rosique, A.F. (San Juan de Alicante)

134 A Single-Center Case Series of Endoscopically Treated Aorto-Gastrointestinal Fistula after Endovascular Aortic Repair: Surgery Is Still the Only Valid Solution Kubesch, A.; Waidmann, O.; Blumenstein, I.; Bechstein, W.O.; Friedrich-Rust, M.; Jung, M. (Frankfurt); Albert, J. (Frankfurt/ Stuttgart); Hausmann, J. (Frankfurt/Hanau)

Clinical Therapeutic Review

142 Endoscopic Decompression in Colonic Distension Belle, S. (Mannheim)

Case Report

149 Recurrence of Pancreatic Ductal Adenocarcinoma after Complete Histopathological Remission Caused by FOLFIRINOX

Höhn, P.; Braumann, C.; Nöpel-Dünnebacke, S.; Munding, J.; Uhl, W.; Luu, A.M. (Bochum)

Letters to the Editor

154 Reply to "Perioperative Alcohol Withdrawal Syndrome: Care Based on Empathy plus Prescriptions Based on Physiology"

Ungur, A.L.; Neumann, T.; Borchers, F.; Spies, C. (Berlin)

156 Perioperative Alcohol Withdrawal Syndrome: Care Based on Empathy plus Prescriptions Based on Physiology

Braillon, A. (Amiens)

158 Erratum

159 PharmaNews

162 Society Bulletins
No. 3

Research Articles

165 Intraoperative Assessment of Gastric Sleeve Oxygenation Using Hyperspectral Imaging in Esophageal Resection: A Feasibility Study

Schwandner, F.; Hinz, S.; Witte, M.; Philipp, M.; Schafmayer, C.; Grambow, E. (Rostock)

171 Postpancreatoduodenectomy Hemorrhage: Association between the Causes and the Severity of the Bleeding

Khuri, S.; Mansour, S.; Obeid, A.; Azzam, A. (Haifa); Borzellino, G. (Verona); Kluger, Y. (Haifa)

180 Laparoscopic Appendectomy: A Safe and Definitive Solution for Suspected Appendicitis

Heise, J.W.; Kentrup, H.; Dietrich, C.G.; Cosler, A.; Hübner, D. Krumholz, W. (Stolberg)

189 Experimental Study of Mechanical Integrity Testing in Stapled Large Bowel: Methylene Blue Leak Test Is Not Inferior to Air Leak Test

Kryzauskas, M.; Degutyte, A.E.; Abeciunas, V.; Lukenaite, B.; Jasiunas, E.; Poskus, E.; Strupas, K.; Poskus, T. (Vilnius)

198 Chemotherapy and Hepatic Steatosis: Impact on Postoperative Morbidity and Survival after Liver Resection for Colorectal Liver Metastases

Mahlmann, J.C.; Wirth, T.C.; Hartleben, B. (Hannover); Schrem, H. (Graz); Mahlmann, J.F. (Valencia); Kaltenborn, A. Klempnauer, J.; Kulik, U. (Hannover)

206 Leg Volume in Patients with Lipoedema following Bariatric Surgery

Fink, J.M. (Freiburg); Schreiner, L. (Freiburg/Hinterzarten); Marjanovic, G. (Freiburg); Erbacher, G. (Hinterzarten); Seifert, G.J. (Freiburg); Foeldi, M.; Bertsch, T. (Hinterzarten)

212 Development and Pilot Validation of an Instrument Assessing Sensorimotor Skills for Percutaneous Gastral Puncture

Engelke, M. (Witten); Grund, K.E. (Tübingen); Schilling, D. (Mannheim); Beilenhoff, U. (Ulm); Stebner, F. (Bochum) Kugler, C. (Freiburg)

Case Reports

219 Preserving a Rare Type of Variant Right Hepatic Artery Combines Surgical Radicality and Intact Liver Perfusion during Pancreatectomy Aghalarov, I.; Lutz, T.; Uhl, W.; Belyaev, O. (Bochum)

222 First Report of a Low-Grade Pseudomyxoma peritonei Originating from Gall Bladder

Prabhu, A. (Namakkal); Brandl, A. (Lisbon); Wakama, S. (Kyoto); Sako, S.; Ishibashi, H. (Kishiwada/Osaka); Nishino, E. (Kishiwada); Yonemura, Y. (Kishiwada/Osaka/Kusatsu)

226 Diffuse Neuromatosis of Intrahepatic and Extrahepatic Bile Ducts as a Rare Cause of Jaundice

Vassos, N. (Erlangen/Mannheim); Perrakis, A. (Magdeburg); Schmid, A. (Erlangen); Croner, R.S. (Magdeburg); Gruetzmann, R.; Agaimy, A. (Erlangen) 
PharmaForum

234 CED: Langzeitdaten nach Wechsel auf Infliximab-Biosimilar

237 PharmaNews

No. 4

Editorial

243 Excess Body Weight and Gastrointestinal Disease Germer, C.-T. (Würzburg); Scherübl, H. (Berlin)

Review Articles

246 Excess Body Weight and Abdominal Hernia

Dietz, U.A. (Olten); Kudsi, O.Y.; Gokcal, F; Bou-Ayash, N.

(Brockton, MA); Pfefferkorn, U. (Olten); Rudofsky, G.

(Brockton, MA/Olten); Baur, J. (Olten); Wiegering, A.

(Würzburg)

Focus Article

254 Excess Body Weight and Gallstone Disease

Stokes, C.S. (Berlin/Potsdam-Rehbrücke); Lammert, F.

(Homburg/Hannover)

Focus Article

261 Excess Body Weight and Gastrointestinal Cancer Risk Scherübl, H. (Berlin)

Focus Article

267 Excess Body Weight and Gastroesophageal Reflux Disease

Thalheimer, A.; Bueter, M. (Zurich/Männedorf); Bueter, M. (Zurich/Männedorf)

Focus Article

273 Excess Body Weight and Metabolic (Dysfunction)Associated Fatty Liver Disease (MAFLD)

Roeb, E. (Gießen)

Focus Article

281 Excess Body Weight and Pancreatic Disease

Wiese, M.L.; Aghdassi, A.A.; Lerch, M.M.; Steveling, A.

(Greifswald)

Focus Article

Systematic Review

287 Impact of Excess Body Weight on Postsurgical Complications

Plassmeier, L.; Hankir, M.K.; Seyfried, F. (Wuerzburg) Focus Article

Interdisciplinary Discussion

298 Interdisciplinary Discussion: Excess Body Weight and Gastrointestinal Disease

Kähler, G.; Otto, M. (Mannheim); Kahl, S. (Berlin); Willeke, F. (Siegen); Sendt, W. (Bremen); Gossner, L. (Karlsruhe)

Focus Article
Clinical Therapeutic Review

302 Liver Transplantation in Malignancies:

A Comprehensive and Systematic Review on

Oncological Outcome

Talakić, E.; Janek, E.; Mikalauskas, S.; Schemmer, P. (Graz)

Research Article

315 Safety of Inguinal Hernia Repair in the Elderly with Perioperative Continuation of Antithrombotic Therapy Hada, G.; Zhang, S.; Song, Y.; Jaiswar, M.; Xie, Y.; Jian, F.; Lei, W. (Chengdu)

323 PharmaNews

327 Society Bulletins

No. 5

Systematic Reviews

329 Ischemic Preconditioning for Liver Transplantation: A Systematic Review and Meta-Analysis of Randomized Controlled Trials

Jakubauskiene, L.; Jakubauskas, M. (Graz/Vilnius); Stiegler, P.; Leber, B.; Schemmer, P. (Graz); Strupas, K. (Vilnius)

338 Optimal Range of Fecal Calprotectin for Predicting Mucosal Healing in Patients with Inflammatory Bowel Disease: A Systematic Review and Meta-Analysis Xiang, B.-J.; Jiang, M.; Sun, M.-J.; Dai, C. (Shenyang)

Review Articles

349 A Comprehensive Review: Molecular and Genetic Background of Indirect Inguinal Hernias Somuncu, S. (İstanbul); Somuncu, Ö.S. (New York, NY)

358 Current Endoscopic Resection Techniques for Gastrointestinal Lesions: Endoscopic Mucosal Resection, Submucosal Dissection, and Full-Thickness Resection

Hoffman, A. (Aschaffenburg); Atreya, R.; Rath, T.; Neurath, M.F. (Erlangen)

372 Excessive Body Weight and Diverticular Disease Böhm, S.K. (Bülach)

383 Targeting the Intestinal Barrier to Prevent Gut-Derived Inflammation and Disease: A Role for Intestinal Alkaline Phosphatase

Kühn, F.; Duan, R.; Ilmer, M.; Wirth, U. (Munich); Adiliaghdam, F. (Boston, MA); Schiergens, T.S.; Andrassy, J.; Bazhin, A.V.; Werner, J. (Munich)

394 Obesity and Gallstones

Parra-Landazury, N.M.; Cordova-Gallardo, J.; Méndez-Sánchez, N. (Mexico City) 
Research Articles

403 A Novel Hybrid Stent with Endoscopic Vacuum Therapy for Treating Leaks of the Upper Gastrointestinal Tract Chon, S.-H.; Töx, U.; Lorenz, F.; Rieck, I.; Wagner, B.J.; Kleinert, R.; Fuchs, H.F.; Goeser, T.; Quaas, A.; Bruns, C.J. (Cologne)

410 Multimodal Treatment of cT3 Rectal Cancer in a Prospective Multi-Center Observational Study: Can Neoadjuvant Chemoradiation Be Omitted in Patients with an MRI-Assessed, Negative Circumferential Resection Margin?

Ptok, H.; Meyer, F.; Gastinger, I. (Magdeburg); Garlipp, B. (Hennigsdorf)

418 Gastric Balloon Implantation as Part of Morbid Adiposity Therapy Changes the Structure of the Stomach Wall

Patrzyk, M.; Sonke, J.; Glitsch, A.; Kessler, R.; Steveling, A.; Lünse, S. (Greifswald); Partecke, L.I. (Schleswig);

Heidecke, C.-D.; Kessler, W. (Greifswald)

426 Hyperspectral Imaging: A New Intraoperative Tool for Pouch Assessment in Patients Undergoing Restorative Proctocolectomy

Jansen-Winkeln, B.; Takoh, J.P.; Chalopin, C.; Maktabi, M.; Lyros, O.; Sucher, R.; Hoffmeister, A.; Teich, N.; Köhler, H.; Gockel, I. (Leipzig)

434 Validation of Tokyo Guidelines 2007 and Tokyo Guidelines 2013/2018 Criteria for Acute Cholangitis and Predictors of In-Hospital Mortality

Mohan, R.; Wei Lynn Goh, S.; Tan, G.W.; Tan, Y.P.; Junnarkar, S.P.; Huey, C.W.T.; Low, J.K.; Shelat, V.G. (Singapore)

Case Reports

443 Pneumoretroperitoneum after a STARR Procedure Performed One Year after a Posterior Colporrhaphy: A Case Report and Review of the Literature Darwich, I.; Melekian, B.; Demirel-Darwich, S.; Willeke, F. (Siegen)

447 Pancreatic Acinar Cell Carcinoma with Germline BRCA2 Mutation and Severe Pancreatic Panniculitis: A Case Report

Dreikhausen, L.; Schulte, N.; Belle, S.; Weidner, P.; Moersdorf, J. Reissfelder, C.; Ebert, M.P.; Zhan, T. (Mannheim)

PharmaForum

452 Morbus Crohn: Erstlinien-Biologikum Ustekinumab im Head-to-Head-Vergleich

454 PharmaNews

No. 6

Editorial

455 Digital Communication Strategies in Visceral Medicine Riemann, J.F. (Ludwigshafen); Teufel, A. (Mannheim)

Focus Article
Review Articles

459 Digital Communication in Visceral Medicine: Regulatory Framework for Digital Communication Burg, F.; Pscherer, A.; Opitz, O.G. (Mannheim) Focus Article

466 Digital Technology in Visceral Medicine: An Overview in Outpatient Care in Germany

Naumann, A. (Dormagen); Tappe, U. (Hamm); Teufel, A. (Mannheim)

Focus Article

472 Artificial Intelligence in Endoscopy

Hann, A.; Meining, A. (Würzburg)

Focus Article

477 Electronic Medical Records for (Visceral) Medicine: An Overview of the Current Status and Prospects Kernebeck, S.; Busse, T.S.; Jux, C. (Witten); Bork, U. (Dresden); Ehlers, J.P. (Witten)

Focus Article

483 Advances in Digital Pathology: From Artificial Intelligence to Label-Free Imaging

Großerueschkamp, F.; Jütte, H.; Gerwert, K.; Tannapfel, A. (Bochum)

Focus Article

492 Clinical Decision Support Systems

Teufel, A. (Mannheim); Binder, H. (Freiburg)

Focus Article

Interdisciplinary Discussion

499 Digital Communication Strategies in Visceral Medicine Riemann, J.F. (Ludwigshafen); Opitz, O.G. (Mannheim); Naumann, A. (Dormagen); Tappe, U. (Hamm); Teufel, A. (Mannheim); Meining, A. (Würzburg) Focus Article

Clinical Therapeutic Review

505 Advanced Robotic Surgery: Liver, Pancreas, and Esophagus - The State of the Art?

Scognamiglio, P.; Stüben, B.-O.; Heumann, A.; Li, J.; Izbicki, J.R.; Perez, D.; Reeh, M. (Hamburg)

Systematic Reviews

511 Lack of Oncological Benefit from Bursectomy in Radical Gastrectomy: A Systematic Review Garg, P.K. (Dehradun); Jakhetiya, A. (Udaipur); Turaga, K.K. (Chicago, IL); Kumar, R. (Rishikesh); Brandl, A. (Lisbon); Rau, B. (Berlin)

521 A Systematic Review of Abdominal Imaging Findings in COVID-19 Patients

Singh, P. (Lucknow); Singh, S.P. (New Delhi); Verma, A.K. (Lucknow); Raju, S.N. (New Delhi); Parihar, A. (Lucknow) 
Research Articles

533 Confocal Laser Microscopy for in vivo Intraoperative Application: Diagnostic Accuracy of Investigator and Machine Learning Strategies

Ellebrecht, D.B. (Großhansdorf/Lübeck); Heßler, N. (Lübeck);

Schlaefer, A.; Gessert, N. (Hamburg)

542 The Psychosocial Burden on Liver Transplant Recipients during the COVID-19 Pandemic

Weber, S.; Rek, S.; Eser-Valeri, D.; Padberg, F. (Munich);

Reiter, F.P. (Munich/Würzburg); De Toni, E.; Hohenester, S.;

Zimny, S.; Rehm, M.; Guba, M.O.; Gerbes, A.L.; Denk, G.

(Munich)
Case Report

550 First Report of a Late Lethal Pulmonary Biliary Embolism following Hepatic Microwave Ablation Jusufi, M.S.; Makridis, G.; Feyerabend, B.; Oldhafer, K.J. (Hamburg)

\section{Acknowledgement to Reviewers}

PharmaForum

556 EC/GEJC: Adjuvante Immuntherapie ergänzt kurativen Behandlungsansatz

558 PharmaNews

563 Society Bulletins
S. Karger

Medical and Scientific Publishers
Disclaimer

The statements, opinions and data contained in this publication are solely those of the individual authors and contributors and not of the publisher and the editor(s). The appearance of advertisements in the journal is not a warranty, endorsement, or approval of the products or services advertised or of their effectiveness, quality or safety. The publisher and the editor(s) disclaim responsibility for any injury to persons or property resulting from any ideas, methods, instructions or products referred to in the content or advertisements.

Drug Dosage

The authors and the publisher have exerted every effort to ensure that drug selection and dosage set forth in this text are in accord with current recommendations and practice at the time of publication. However, in view of ongoing research, changes in government regulations, and the constant flow of information relating to drug therapy and drug reactions, the reader is urged to check the package insert for each drug for any change in indications and dosage and for added warnings and precauin indications and dosage and for added warnings and precau-
tions. This is particularly important when the recommended agent is a new and/or infrequently employed drug.
All rights reserved

No part of this publication may be translated into other languages, reproduced or utilized in any form or by any means, electronic or mechanical, including photocopying, recording, microcopying, or by any information storage and retrieval system, without permission in writing from the publisher or in the case of photocopying, direct payment of a specified fee to the Copyright Clearance Center (see "General Information").

(c) Copyright 2021 by S. Karger AG,

$\mathrm{CH}-4009$ Basel (Switzerland)

Printed on acid-free and non-aging paper (ISO 9706) 